\title{
Influence of Rainfall on Temperature and Salinity of the Ocean Surface
}

\author{
Kristina Katsaros and Konrad J. K. Buettner \\ Dept. of Atmospheric Sciences, University of Washington, Seattle
}

(Manuscript received 17 September 1968, in revised form 21 October 1968)

ABSTRACT

\begin{abstract}
Falling rain changes sea surface conditions, because of its different salinity, different temperature, and its momentum. Experimental evidence of the action of these three factors has been gathered using artificial and natural rain falling on a salt water tank. Big drops cause substantital mixing; smaller ones create a very stable surface layer.
\end{abstract}

\section{Introduction}

Satellite infrared radiometers can yield data on surface emission of the oceans. Future very high resolution infrared instruments promise measurements over areas of only some $700 \mathrm{~m}$ in diameter. This would permit one to monitor, for instance, cloud-free segments between raining cumuli. Since the emissivity of water for these spectral areas is very high and constant, the received signal depends essentially on the temperature of the emitting layers, averaged over a a depth of no more than a few microns; atmospheric transmission and emission, of course, must also be considered (e.g., Clark, 1967). The surface or skin layer may have a temperature quite different from that measured in a bucket or by trailing thermometers or thermistors, as discussed by many authors (e.g., Woodcock and Stommel, 1947; Jarvis and Kagarise, 1962; McAlister 1964; Saunders, 1967), and this difference should be considered for many applications. This skin temperature can be greatly altered by precipitation falling on a warmer or cooler sea. $\mathrm{Ob}$ servations from ships show that this temperature and salinity deviation may persist for some time. This persistence is caused by the stability of the stratification with fresher water over more saline water.

A group of cumuli shedding warm rain on antarctic waters would leave a trail of warm signals in the wake of its motion. These signals could be compared with cold signals and normal ocean signals.

There is another interesting aspect of the steep temperature gradient in the first $10-100 \mu \mathrm{m}$. If the skin temperature is only $0.4 \mathrm{C}$ colder than deeper lavers, as measured by McAlister (1964), the near surface relative humidity of the air would increase by $2.3 \%$ (at 30C) as compared to air in equilibrium with the temperature of deeper layers. There would be an equal amount of relative humidity depression caused by a surface salinity change of $3.5 \%$.

\section{Literature survey}

There are a number of indications in the literature relating to changes in the radiative sea surface temperature, when rain of a temperature different than the ocean has fallen near the time of observation. Franceschini (1964) and Boudreau (1965), for instance, measured the radiative sea surface temperature from shipboard. Franceschini noted a warming of the radiative surface temperature in antarctic waters in connection with precipitation while Boudreau obtained a difference of $-1 \mathrm{C}$ between the radiative and bulk sea surface temperatures immediately after a rain shower in the Caribbean. Before the rain the difference had been $-0.5 \mathrm{C}$. Squire (1964) observed a decrease in the reading of his airborne radiometer as the aircraft went through rain or hail; however, the cold hydrometeors in the air may have had an effect in addition to a sea surface temperature change.

Using visible light and near infrared, changes in sea surface reflectivity after a rain shower were detected by photogrammetric techniques by Yost and Wenderoth (1967); whether the observed pattern was due directly to a reduction in sea surface salinity and temperature cannot be asserted. Theoretical values using Fresnel formulas for the possible change in reflectivity at these wavelengths due to dilution and temperature reduction, would give changes in the order of tenths of a per cent only, even at large angles from normal.

Small changes in the bulk values for sea surface temperature and salinity were reported from several oceanographic expeditions (Schott, 1893; Visser, 1938; Neumann, 1940).

There is thus much evidence that the effects of precipitation should be considered when studying the uppermost surface of the ocean. While the details of the interaction between precipitation and the sea surface are not well understood, we may anticipate what the important parameters could be. The magnitude of the 


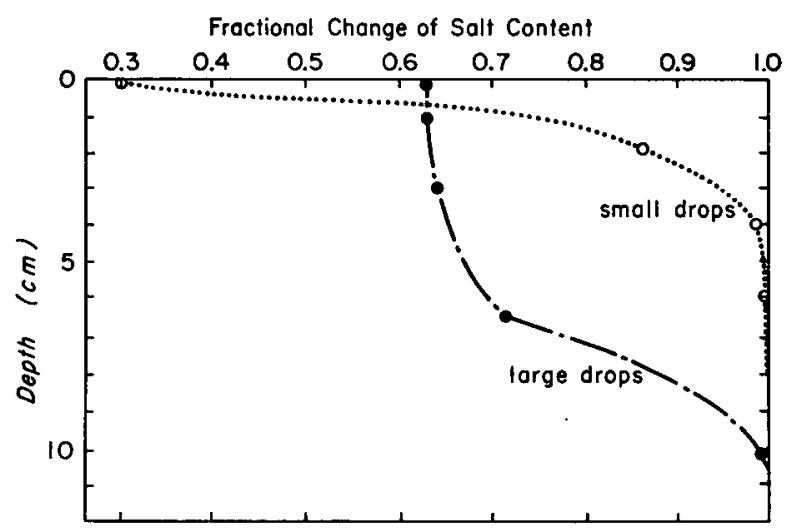

FIG. 1. Laboratory tests of salt content change at different depths in a salt water tank into which artificial rain has fallen. The abscissa is the fractional change of salinity (see text), where a value of 1 corresponds to undiluted salt water and a value of 0 to pure rain water. Heavy line: drop size $3 \mathrm{~mm}$, rain rate $1.7 \mathrm{~cm} \mathrm{hr} \mathbf{r}^{-1}$, time $90 \mathrm{~min}$ after start of rain; dotted line: drop size $\leq 1.2 \mathrm{~mm}$, rain rate $0.42 \mathrm{~cm} \mathrm{hr}^{-1}$, time $2 \mathrm{hr}$ after start of rain.

rain-caused change in the radiative sea surface temperature is expected to be proportional to the temperature difference between the rain and the sea. Similarly, the magnitude of the dilution would depend on the salinity difference between the ocean and the rain, and thus on the ocean salinity itself.

Both temperature and salinity effects would depend on 1) the duration and intensity of the rain, and 2) the turbulence in the sea near the surface. The turbulence depends in turn on the sea state and surface current, and on the stability of the density structure near the surface. In addition, there would be the turbulence caused by the impact of the raindrops.

\section{Experimental design}

A salt water tank was used to measure changes of temperature and salinity profiles, while artificial and natural rain was falling into the tank. The cylindrical tank was $43 \mathrm{~cm}$ in diameter and $39 \mathrm{~cm}$ deep; it was insulated with $1 \mathrm{~cm}$ thick fiberglass and covered with polyethylene to avoid wetting. It was filled with sodium chloride solution to simulate the ocean. In the laboratory the "rain" was produced by a tap water drip from 9-17 hypodermic needles, $2.4 \mathrm{~m}$ above the salt water surface, extending from horizontal pipes at the bottom of a smaller, well insulated tank, which was hung from the ceiling. The rain tank could be made to turn at $2 \mathrm{rpm}$. The drops, falling by their own weight, were approximately $3 \mathrm{~mm}$ in diameter; they arrived at the salt water surface with a velocity of $5.5 \mathrm{~m} \mathrm{sec}^{-1}$, which is $60 \%$ of the terminal velocity for this drop size. In order to produce smaller drops a fine screen was placed $35 \mathrm{~cm}$ below the needles, and the large drops were broken up into drops of $1.3 \mathrm{~mm}$ diameter and smaller, when passing through the screen. The salt water tank was also placed out-of-doors in order to observe the effect of natural rainfall.

The temperature in the salt water tank was measured at 6 levels with copper constantan thermocouples, and the radiative surface temperature was measured with a thermistor bolometer, the Barnes PRT5, which operates in the 8-14 $\mu$ wavelength region. Small samples of the water in the salt water tank were extracted through hypodermic needle tubing at 6 levels, and were later analyzed for salt content by an electric conductivity measuring bridge circuit. The rain temperature was measured by collecting a few drops in a cutoff syringe with a fine thermocouple inserted near the outlet, and the rain amount was read on a millimeter scale mounted on the side of the tank.

The salt content $\sigma$ is given in analogy with sea water salinity in terms of the density at a certain temperature; thus, $\sigma_{T}=\left(\rho_{T}-1\right) 10^{3}$, where $\rho$ is the density (gm $\mathrm{cm}^{-3}$ ) and the subscript $T$ indicates temperature $\left({ }^{\circ} \mathrm{C}\right)$. The fractional change (fr. ch.) in salt content due to rain may now be defined by

$$
\text { fr. ch. }=\left(\sigma_{T}-\sigma_{T, R}\right) /\left(\sigma_{T, 0}-\sigma_{T, R}\right),
$$

where $\sigma_{T, 0}$ is the initial value of the sea water salt content, and the subscript $R$ refers to rain; $\sigma_{T, R}=0$ for clean rain at $4 \mathrm{C}$.

Similarly, temperature can be put on a $0-1$ scale. The fractional change in temperature is given by $\left(T-T_{R}\right) /$ $\left(T_{0}-T_{R}\right)$, where $T_{0}$ is the initial temperature of the salt water, $T_{R}$ the rain temperature and $T$ the temperature of the tank water at various depths. This assumes that density and specific heat are approximately equal for rain and salt water.

\section{Results}

Fig. 1 shows the salt content profiles for two typical laboratory rain experiments: one with uniform large

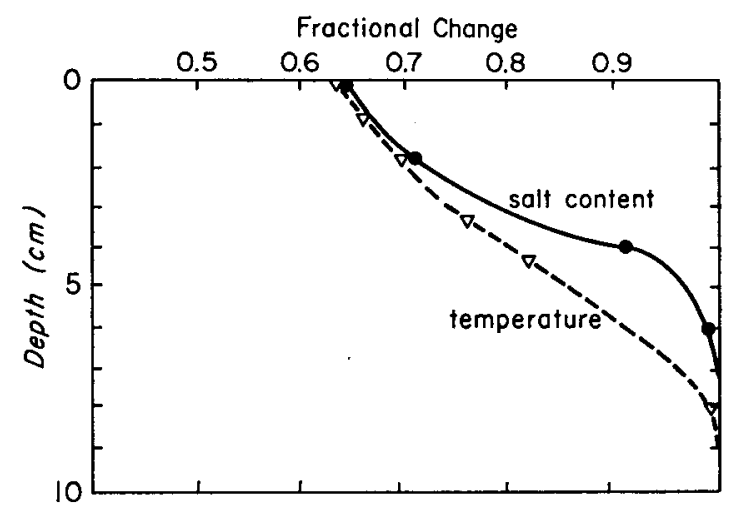

FIG. 2. Fractional change of temperature and salinity for an artificial rain with drops $\leq 3 \mathrm{~mm}$. Initial temperature of the tank $21.0 \mathrm{C}$, average rain temperature $15.5 \mathrm{C}$, dry bulb temperature of the air $24.5 \mathrm{C}$, wet bulb $18.0 \mathrm{C}$; rain rate $1.0 \mathrm{~cm} \mathrm{hr}^{-1}$; time $75 \mathrm{~min}$ after start of rain. 
rain drops, and one with smaller drops. The large drops cause very efficient mixing down to a depth of $7 \mathrm{~cm}$, while the smaller ones cause a large change in surface salinity, but a much less pronounced change at depth. The temperature profiles generally follow a similar shape, as can be seen in Fig. 2, but the temperature effect penetrates to greater depths due to the fact that below the region characterized by turbulence caused by the rain drops, molecular transfer takes place, and the value of the molecular diffusion coefficient for heat is two orders of magnitude larger than that for salt. The shape of the temperature and salinity profiles differs for the same reason. Numerical solutions to the governing differential equations bear this out.

Superimposed on the heat transfer due to the rain is the effect of radiative surface heat transfer, and conductive and latent heat exchange between the atmosphere and the salt water. A $0.1 \mathrm{C}$ cooler film at the surface before the rain indicated a small surface heat loss from the tank. The nondimensional representation of Fig. 2 shows the importance of the two cooling mechanisms for this particular laboratory case. The integrated area between the curves and the depth scale would have been equal were it not for the surface heat loss. The area between the curves in Fig. 2 thus represents the cooling due to surface heat loss.

In Fig. 3 we see the change with time of the temperature at the surface, and at 2 and $15 \mathrm{~cm}$ depths, for an experiment with the tank placed outdoors. The tank temperature was initially $17 \mathrm{C}$ throughout, and the dry bulb and wet bulb temperatures of the air $11.6 \mathrm{C}$. The rain temperature can be assumed equal to the wet bulb. The surface temperature was measured with the radiometer, those at depth with thermocouples. The surface temperature decreases rapidly at first due to the cold rain and surface heat loss, and then levels off as the diffusion of heat from below is increased both by the mechanical stirring caused by the rain and the larger temperature gradient. The heat flux across the surface is also substantially reduced as the temperature decreases.

The fact that the time rate of temperature decrease at $15 \mathrm{~cm}$ is much weaker indicates that more of the cold rain has mixed near the surface, and that convection has been suppressed by the stability of the fresher surface water. After the rain has stopped the radiative temperature remains constant for $5 \mathrm{~min}$, while the turbulent motions persist; it then decreases creating a temperature gradient below the water surface. This gradient produces an upward heat flux at the surface, which is necessary to balance the heat losses to the outside environment. In this case the surface heat loss seems to have been caused by radiation, since the radiative surface temperature is lower than that of the saturated air.

The outdoor observations, in general, agreed with the findings of the laboratory experiments, but the range of drop sizes present in a natural rain tended to smooth the temperature and salinity profiles between the two extremes in Fig. 1.

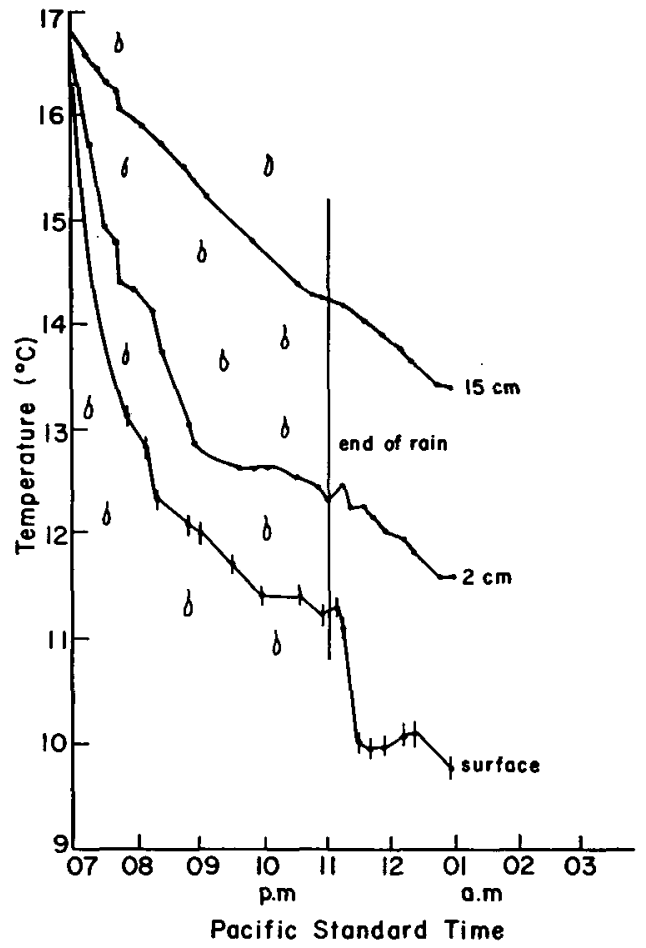

Fig. 3. Temperature at various depths in the salt water tank as a function of time for the natural rainfall of 3-4 February 1968 in Seattle. The surface temperature was measured with the PR'5 radiometer, the other two by thermocouples. Rain in the amount of $1.4 \mathrm{~cm}$ fell during an approximate 4 -hr period with rain intensity decreasing during the last hour. The dry and wet bulb temperatures of the air were $11.6 \mathrm{C}$ at the beginning of the rain, decreasing to $10.6 \mathrm{C}$ at the end. The rain temperature can be assumed equal to the wet bulb temperature.

Since a very stable density stratification develops as a result of the rain, even strong surface cooling will not cause convection. Because of the large value for molecular heat conduction in water $\left[1.3 \times 10^{-3} \mathrm{cal} \mathrm{cm}^{-1} \mathrm{sec}^{-1}\right.$ $\left.\left({ }^{\circ} \mathrm{C}\right)^{-1}\right]$, the radiative temperature at the surface will adjust to the environmental influences and reach a quasi steady state within an hour's time. On the other hand, molecular salt diffusion is a very slow process as mentioned above. Even with the tank outdoors and strong winds, the salinity gradients remained almost undisturbed for days. It was evaporation at the surface, more than diffusion, which finally eroded the salinity stratification.

Ewing and McAlister (1960) have shown that the cool film exists at the sea surface even under turbulent conditions. After their pump, which produced turbulence mechanically, had been turned off, the cool film reestablished itself within $5 \mathrm{sec}$. In view of this it may be that the most significant effect of a rain containing large drops is that it breaks up this cool film. A rain consisting only of small drops, on the other hand, may have a chance to remain near the surface, and therefore influence the radiative temperature with its own temperature. 
Acknowledgments. This research was carried out with the support of the National Aeronautics and Space Administration under Grant NsG-632.

\section{REFERENCES}

Boudreau, R. D., 1965: Skin temperature of the sea as determined by radiometer. Ref. 65-15T, A and M Proj. 286, Texas A\&M Research Foundation, College Station, $68 \mathrm{pp}$.

Clark, H. L., 1967: Some problems associated with airborne radiometry of the sea. Appl. Optics, 6, 2151-2157.

Ewing, G., and E. D. McAlister, 1960: On the thermal boundary layer of the ocean. Science, 131, 1374-1376.

Franeschini, G. A., 1964: Some factors influencing the skin temperature of the sea and its measurement by infrared thermometer. Techniques for infrared survey of sea surface temperature, Bur. of Sports, Fisheries and Wildlife, Circ. 202, 17 pp.

Jarvis, N. L., and R. E. Kagarise, 1962 : Determination of the surface temperature of water during evaporation studies. A comparison of thermistor with infrared radiometer measurements. J. Colloid. Sci., 17, 501-511.

McAlister, E. D., 1964: Infrared-optical techniques applied to oceanography. I. Measure of total heat flow from the surface. Appl. Optics, 3, 609-612.

Neumann, G., 1940: Die ozeanographischen Verhaltnisse an der Meersoberfläche im Golfstromektor nördlichund nordwestlich der Azoren. Aus den Wiss. Erg. d. Intern. Golfstrom-Unternehmung, 1938, Ann. Hdyro. Mar. Meteor. Beitr., 1-87.

Saunders, P. M., 1967 : The temperature at the ocean-air interface. J. Atmos. Sci., 24, 269-273.

Schott, G., 1893: Wissenschaftliche Ergebnisse einer Forschungsreise zur See ausgefuhrt in den Jahren 1891 und 1892. Petermanns Mitteilungen, Erganzungsheft No. 109, 12-15 and 28-29.

Squire, J. L. Jr., 1964: Observations of some physical factors affecting the use of an airborne radiometer. Techniques for infrared survey of sea temperature, Bur. of Sports, Fisheries and Wildlife, Circ. No. 202, $16 \mathrm{pp}$.

Visser, S. W., 1938: The Snellius Expedition in the Eastern part of the Netherlands East Indies, 1929-30. Vol. 2, part 4, p. 24, and Vol. 3, pp. 13-14, Leiden, E. J. Brill.

Woodcock, A. H., and H. Stommel, 1947 : Temperatures observed near the surface of a fresh-water pond at night. J. Meteor., 4, 102-105.

Yost, E. F., and S. Wenderoth, 1967: Multispectral color aerial photography. J. Amer. Soc. Photogrammetry, 33, 1020-1033. 